\title{
Erratum
}

\section{Nonlinear Taxes in a Life-Cycle Consistent Model of Family Labour Supply}

Thomas Aronsson and Magnus Wikström

Department of Economics, University of Umeå, 90187 Umeå, Sweden

Because of a programming error, Tables 4.1, 4.2 and 4.3 in our paper (Empirical Economics 19,1-17) are not correct. The model is

$$
\begin{aligned}
h_{m}= & \delta_{1}+\gamma_{1} w_{m}+\alpha w_{f} \\
& +\beta_{1}\left[\mu+\delta_{1} w_{m}+\delta_{2} w_{f}+0.5\left(\gamma_{1} w_{m}^{2}+\gamma_{2} w_{f}^{2}+2 \alpha w_{m} w_{f}\right)\right] \\
h_{f}= & \delta_{2}+\gamma_{2} w_{f}+\alpha w_{m} \\
& +\beta_{2}\left[\mu+\delta_{1} w_{m}+\delta_{2} w_{f}+0.5\left(\gamma_{1} w_{m}^{2}+\gamma_{2} w_{f}^{2}+2 \alpha w_{m} w_{f}\right)\right]
\end{aligned}
$$

where $\delta_{1}+\delta_{10}+\delta_{11} A(m)$ and $\delta_{2}=\delta_{20}+\delta_{21} A(f)+\delta_{22} N C . A(j)$ is a dummy variable taking the value one if spouse $j$ is above 55 years of age and zero otherwise while NC is the number of children living at home. This is a slight change in comparison with the original model, which included education in-

Table 4.1. Parameter estimates

\begin{tabular}{lccc}
\hline Item & Males $(j=1)$ & Coefficient & Females $(j=2)$ \\
\hline$\delta_{j 0}$ (constant) & 1.554 & & 0.079 \\
& $(68.18)$ & $(3.17)$ \\
$A(j)$ & -0.721 & -0.774 \\
No. of Children & $(-18.87)$ & $(-14.09)$ \\
& & -0.217 \\
$\gamma_{j}$ (Wage) & 0.027 & $(-10.86)$ \\
$\beta_{j}$ (Income) & $(7.92)$ & 0.070 \\
$\alpha$ (Cross Wage) & $-1.64 \cdot 10^{-5}$ & $(18.69)$ \\
& $(-0.06)$ & & $-3.62 \cdot 10^{-4}$ \\
& & & $(-1.14)$ \\
\hline
\end{tabular}

$\sigma_{m}=0.614$

$\sigma_{j}=0.890$

$\sigma_{m f}=0.012$

$\log L=-4858.149$

$t$-values in parenthesis 
stead of age. Since both age and education are included in the wage equations (see Appendix), we are not able to control for separate effects of both these variables on the hours of work. Replacing education in the original model with age made it more easy to locate the maximum of the likelihood function.

The qualitative results in terms of the signs of wage and income effects are similar to those reported in the paper. On the other hand, the size of the estimated parameters differ. This is particularly so for income effects and cross: wage effects.

Table 4.2. Elasticities

\begin{tabular}{|c|c|c|c|}
\hline Item & $h_{m}$ & Elasticity of & $h_{f}$ \\
\hline$w_{m}$ & 0.231 & & 0.072 \\
\hline$w_{f}$ & 0.050 & & 1.300 \\
\hline$\mu$ & $-0.18 \cdot 10^{-3}$ & & -0.007 \\
\hline
\end{tabular}

Table 4.3. Consequences of taxation

\begin{tabular}{llc}
\hline Regime & $h_{m}$ & $h_{f}$ \\
\hline Present Case & 1925 & 1062 \\
Post Reform & 1933 & 1078 \\
\hline
\end{tabular}

Note: The hypothetical reform is to decrease the marginal tax rate by one percentage point in each tax bracket.

\section{Appendix}

Table A1. Wage equations

\begin{tabular}{|c|c|c|}
\hline Variable & Males & Females \\
\hline Constant & $\begin{array}{l}-15.888 \\
(-1.85)\end{array}$ & $\begin{array}{r}8.482 \\
(1.72)\end{array}$ \\
\hline Age & $\begin{array}{c}1.894 \\
(5.22)\end{array}$ & $\begin{array}{l}1.008 \\
(4.50)\end{array}$ \\
\hline Age squared & $\begin{array}{r}-0.019 \\
(-4.73)\end{array}$ & $\begin{array}{l}-0.011 \\
(-4.17)\end{array}$ \\
\hline E1 & $\begin{array}{c}7.163 \\
(2.10)\end{array}$ & $\begin{array}{l}-2.051 \\
(-1.09)\end{array}$ \\
\hline E2 & $\begin{array}{l}11.606 \\
(6.36)\end{array}$ & $\begin{array}{r}1.974 \\
(0,96)\end{array}$ \\
\hline E3 & $\begin{array}{c}0.454 \\
(0.23)\end{array}$ & $\begin{array}{l}6.428 \\
(2.96)\end{array}$ \\
\hline$R^{2}$ adj. & 0.153 & 0.122 \\
\hline
\end{tabular}

Note: $t$-values are given within parenthesis. The three educational dummy variables E1, E2 and E3 represent, respectively, elementary school, high school and post high school education. 